\title{
Using Mobile Technologies for Enhancing Student Academic Experience: University of Jordan Case Study
}

\author{
http://dx.doi.org/10.3991/ijim.v10i1.4809 \\ Hassan Mohammad ${ }^{1}$, Alhosban Fuad ${ }^{2}$ Mou'ath Hourani ${ }^{1}$ \\ ${ }^{1}$ Al-Ahliyya Amman University - Jordan \\ ${ }^{2}$ Saudi Electronic University - Saudi Arabia
}

\begin{abstract}
This paper presents an approach to enhance students' academic engagement with their university, as well as assisting them in understanding their current academic state by using mobile technologies. This approach simplifies the presentation, awareness of university rules and regulation in regards to graduation requirements, in credit hour system, through the development of a friendly mobile environment called UniApp.
\end{abstract}

A test case is presented of an interactive mobile learning (mlearning) environment in higher education institutions that adhere to university rules and regulations. Normally, students login frequently to their university account in order to use some of the provided faciliies, such as marks and registered modules. However, students need to be aware of what they are studying and what learning outcome they need to achieve. They also need to be aware of how this can benefit them in completing their major, as well as having an enjoyable learning experience.

Index Terms - Interactive Educational Environment, Mobile Learning, Student Empowerment, Information Extracting, UniApp Approach.

\section{INTRODUCTION}

Universities are currently using a centered approach that presumably provides an interactive learning environment suitable for its students. However, the current approach normally ignores the students' needs and their way of living in the technology era. A lack of communication between universities and their students is emerging, as the current learning environments have no appealing visual presentation, and are not open for students' feedback. In order to change this, universities need to change the way they communicate with students, and adapt a student centered model of information delivery. This can be accomplished by enhancing and updating the communication means between universities and their students through a mobile based virtual learning environment.

Students' planning of their own schedule for next semester that suits their interests and meets overall graduation requirements is a difficult to achieve task, that requires a consistent assessment by their mentors. The changing of requirements, replacement modules, changing courses within own faculty, and other factors can often lead to inadequate scheduling.

The use of On-the-Spot m-learning tool that can help students in identifying inaccuracies in module registration and comparing available options, would bridge the gap between students and the university, and will assist them in following the right direction for quick and successful completion of a degree.

With the use of a self-online registration system, students are left unaware of the rules, regulations, and guidelines of the university. Students then start to stumble around, and look for advice from peers or mentors (if any available). In credit-hour-system, it is expected to find a student who knows nothing about the predecessor of the current module he is taking and what is the next module he is supposed to be taking to complete his study on time. Student awareness of current academic condition will enhance their future module registration and scheduling. This method of self-assessment will reduce the pressure on academic mentors as well as giving the student the confidence in making crucial choices based on the information they have without assistant.

\section{BACKGROUND}

Many universities solely depend on their Virtual learning environments (VLE) to communicate with students. VLEs are considered as important tools in education, both in theory and practice. According to Weller, M. "a wellmaintained VLE should enable students of all learning styles to receive the best possible education as well as maintaining a continuous relationship with their universities"[1].

Students tend to look at VLE resources simply as online versions of lecture notes rather than as a source of additional information to further their understanding [2]. On the other hand, some VLEs are built to enable students to check their up to date information regarding university life, such as grades, absences details, timetable, exam timetable, etc.

Mobile devices or Smartphones nowadays are widely used and provide great communication and multimedia capabilities, which make the delivery of learning activities and out of class interaction a more realistic approach [3]. $\mathrm{M}$-learning can provide just in time learning on the move. According to eMarketer, there is, and would be, a widespread of Smartphone usage across the globe with more than one-third of the world residents will have a smartphone by 2018 [4], see Fig. 1.

Smartphones have become increasingly popular and even more essential personal device to have, therefore, a wide number of teaching and learning applications have been developed for achieving such goals [5]. Due to that, 


\begin{tabular}{|c|c|c|c|c|c|}
\hline \multicolumn{6}{|c|}{$\begin{array}{l}\text { Smartphone User Penetration Worldwide, by Region, } \\
2013-2018 \\
\% \text { of population }\end{array}$} \\
\hline & 2013 & 2015 & 2016 & 2017 & 2018 \\
\hline North America* & $45.1 \% \quad 51.3 \%$ & $56.7 \%$ & $60.5 \%$ & $64.0 \%$ & $66.5 \%$ \\
\hline Western Europe* & $39.5 \% \quad 47.3 \%$ & $54.9 \%$ & $60.5 \%$ & $64.7 \%$ & $67.3 \%$ \\
\hline Central \& Eastern Europe & $26.7 \% 36.9 \%$ & $44.2 \%$ & $51.7 \%$ & $58.2 \%$ & $62.4 \%$ \\
\hline Latin America & $19.0 \% \quad 24.1 \%$ & $29.6 \%$ & $34.3 \%$ & $39.1 \%$ & $43.2 \%$ \\
\hline Asia-Pacific & $19.3 \% 23.9 \%$ & $27.1 \%$ & $29.9 \%$ & $32.5 \%$ & $34.9 \%$ \\
\hline Middle East \& Africa & $6.9 \% \quad 8.9 \%$ & $10.8 \%$ & $12.2 \%$ & $13.6 \%$ & $14.8 \%$ \\
\hline Worldwide* & $19.8 \% \quad 24.5 \%$ & $28.2 \%$ & $31.3 \%$ & $34.2 \%$ & $36.5 \%$ \\
\hline \multicolumn{6}{|c|}{$\begin{array}{l}\text { Note: individuals of arty age who own at least one smartphone and use the } \\
\text { smartphone's) at least once per month; "forecast from Aug } 2014 \\
\text { Source: eMarketer, June \& Aug } 2014\end{array}$} \\
\hline 178404 & & & & W.eMarke & ter.com \\
\hline
\end{tabular}

Figure 1. Worldwide Smartphones Usage 2013-2018 [4]

m-learning became a promising environment that enhances and optimizes learning by utilizing pre-existing information systems and deliver them in a contextual, more meaningful manner.

One major issue for using Smartphones to access VLEs is the network coverage and infrastructure of the universities wireless network [6]. As well as the cost of using own network bandwidth to download academic materials. Therefore, a potential need rose to create cost effective mobile information systems directly for students without the necessity of having continuous internet access available.

As for engaging students in higher education, developing an environment that engage student with university or using m-learning environment is a challenge; not only for infrastructure network limitation, but students consider their mobiles as a personal device. In fact, student having mobiles as the ultimate personal device means there is a strong sense of personal space which limits their perception of using them to engage with academic practices [6]. In this paper, we present an environment that aim to ease the process of gaining all needed information for students for them to be engaged with their university.

Enhancing student engagement with the university environment can also be achieved providing a sense of empowerment [7]. Empowerment means having more responsibility and control over learning environment to adapt for the students' needs, and providing them with the ability to create their own university experience. The empowerment of students is revealed through everyday practices within university life. This achieved by allowing them to reflect and develop a dialogue and organizes both, learning and extracurricular activities.

One of the key issues that need to be considered when developing m-learning environment is to make sure that such environment adhere to university rules and regulations, and do not, under any circumstances, expose both student and university privacy throughout the interaction process. It is clearly understood that developing such environment means allowing users to access sensitive information stored on university servers which make these servers vulnerable to data exposure and hacking [8]. Therefore, university liability must be reduced by finding a safe alternative way to gain information without the need to access the actual database. This can be achieved by the use of web parsers for Information Extraction.

There are few similar applications used by universities that try to provide mobile based access to university either study materials or social events. One example is the University of Miami iPhone mobile application. They provide students with all sport and social events, as well as a go around service that provide directions to go around campus and shuttles schedule [9]. Their approach can be of some use however; maintaining all the application updates can be extremely difficult, as the application will need continuous updates to be rolled out to users. Another example is the University of Alabama mobile application that provides students with information about social activities and access to class schedules, including times, locations, and instructors and their contact details [10]. However, such as the previous example, it needs extensive updates, as well as special access permission to university own servers to pull out class information. In this paper we present a new approach, UniApp Approach, which tackles some of issues faced by different mobile applications.

\section{UNIAPP APPROACH, DESIGN AND IMPLEMENTATION}

We define UniApp approach as an m-learning environment that enables students to use on-the-go and one click away tool that help students with identifying the most accurate steps during the process of online registration of their modules in a credit hours system. The approach will help students' in understanding their current academic condition, and increase their sense of empowerment over learning environments to adapt with their needs. Finally, the approach presents a safe alternative way to gain relevant information without the need to access secured university databases. All of these would enhance students' academic engagement with their universities.

UniApp is based on providing students with many important services, tools, study plan, registered term schedule and their module's based information such as grades, marks, class location, instructor information, and course information. Such approach will empower students' confidence in planning their future academic study and academic engagement. To achieve such approach, all these services and tools should be provided through an interactive m-learning environment. This environment is a one click away; and accessible through their mobile devices anywhere at any time. At the same time, UniApp also adapts with the university portals security and privacy rules; meaning that there will be no need to have access to private information on university servers.

The first step in developing a test environment for our UniApp approach was to conduct interviews with university information technology (IT) department. The aim was to acquire an in-depth knowledge of students' data presentation and university own rules and regulation regarding the access of such data. During the interviews, the IT specialist made it clear that no access to student data will be permitted, and they only allows students to access their information using their credentials (user name and password). Therefore, the concept of UniApp was based on extracting legible information.

Information Extraction often involves syntactic processing of online data. By collecting a sequences of cascades of rules, and deterministically analyze the text, then building unambiguous structures [9]. Then the presented data can be summarized and presented in an easy to understand manner. In this research, information extraction 


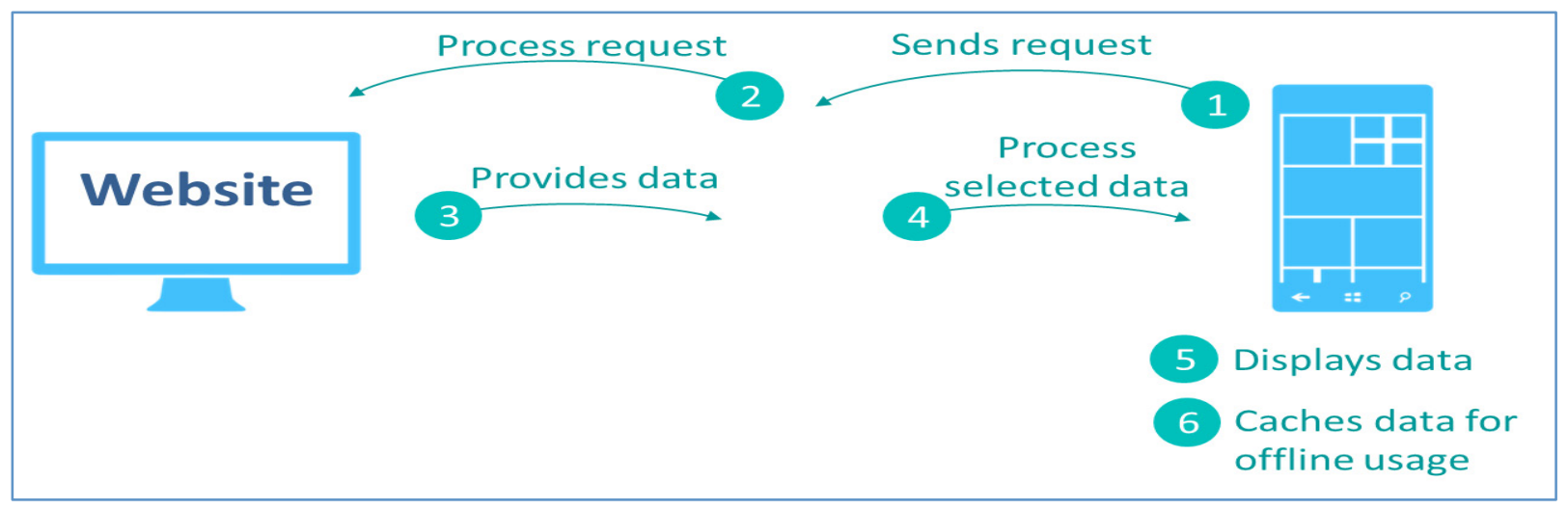

Figure 2. Information Extraction Process

is used to collect student data from the university portal to present it to students in a simplified and easy to track way. Fig. 2 shows the process of information extraction from the university portal. The mobile device sends request to the university website then extract all required data. Then the UniApp will process the data, cache it and present it through the application interface.

The implementation of the UniApp is presented through the development of a mobile application called UJApp. The UJApp is specifically customized for the University of Jordan, which is considered as the most prestigious university in Jordan. The UJApp consists of two main parts; the social part, and academic. Both parts were made simple to use yet contained all the information needed by students. The social part of the application consists of News, Announcements, and the Academic Calendar Fig. 3 and Fig. 4 shows snapshots of the social part of UJApp.

As shown in Fig. 4, all university announcement posted on the university website will be shown to the student in reverse chronological order (newest to oldest).

Both "News and Announcements" screens are considered as crucial part of the UniApp application. Having the same design and access features, both screens can be accessed by tapping on the side navigation menu of the application.

News and Announcements screens were created to display the university news and announcements feeds list. Each list item will then show the students the full article related to that feed.

As for the academic calendar screen (Fig. 5), it was created to assist students to keep track on the university important dates and information related to the exams' timetable, module registration period and their regulations. The design of the screen was created in a way that when a student select the desired academic term, the list will be expanded to show all the planned events and important dates related to that term.

The second part of the UJApp application consisted of the academic related functionalities, such as modules details, grades, and the academic study plan.

Fig. 6 shows a snapshot of study plan screen. UJApp groups module into different types according to the student study plan. Whenever a student completes any of these groups, the application will mark this group as complete and they are no longer need to register to any of the modules within that group. This part of the application is very crucial to achieve the UniApp approach, as one of the main issues that cause inaccuracy in module registration.

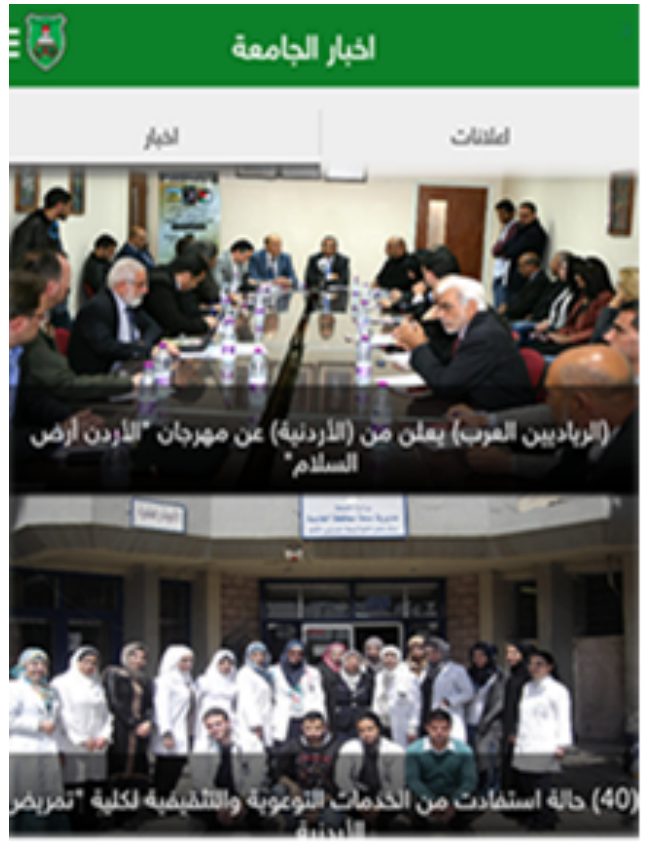

Figure 3. A snapshot of news page

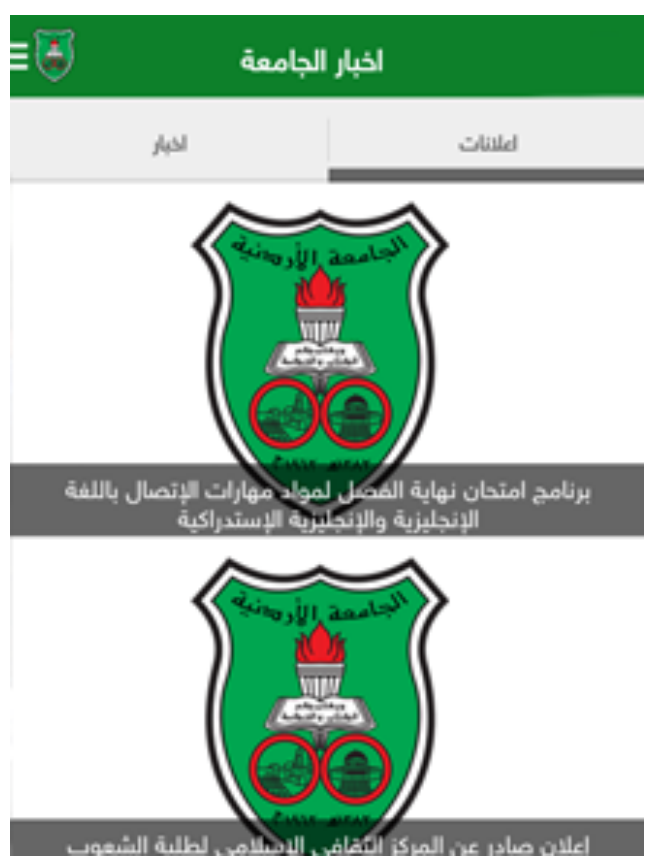

Figure 4. A snapshot of Announcements page 


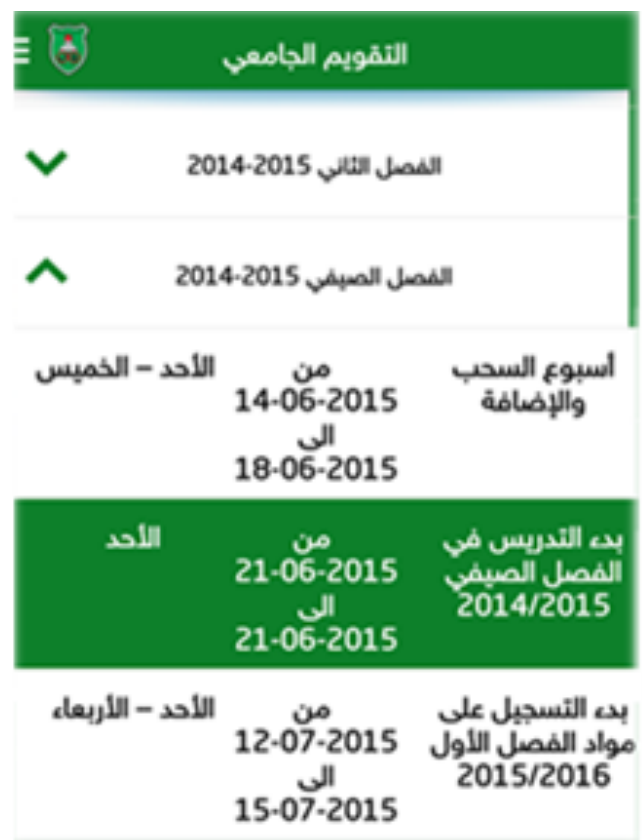

Figure 5. A snapshot of academic calendar screen

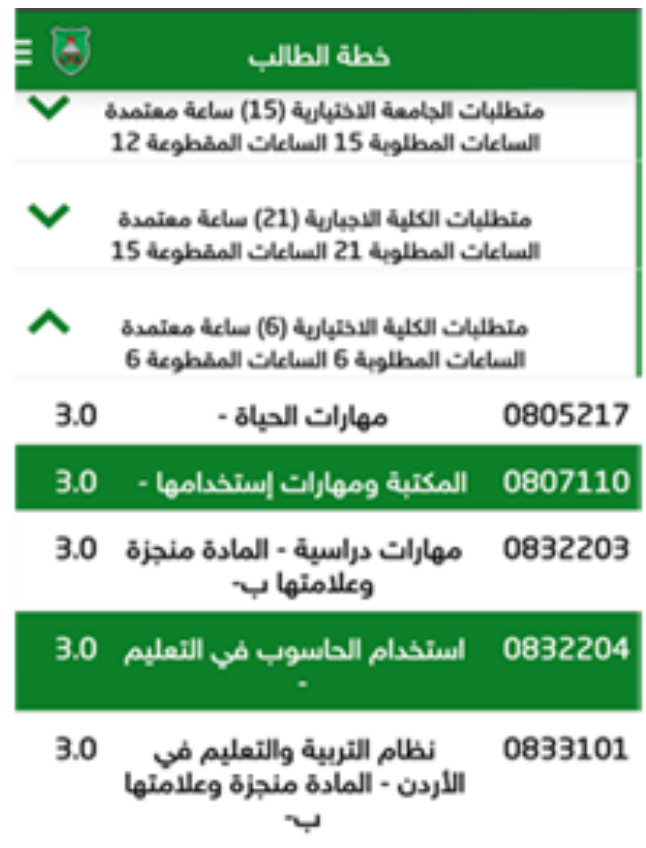

Figure 6. A snapshot of study plan screen

Students' module timetable for the current academic term, as well as the details of each registered module can also be viewed through the student schedule screen. Accessed by tapping on student schedule option from the UJApp side navigation menu, students can view the list of module that they are registered with in the current term as shown in Fig. 7. The module details screen provide students with the ability to set an alarm to remind them before the lecture starts, as well as providing them with the location of the lecture.

After completing each academic term, students can access the term's results page. In this page, student can choose any previously completed academic terms. Then he can view a detailed list of all modules' marks, as well as that term average grad and cumulative grade. As shown

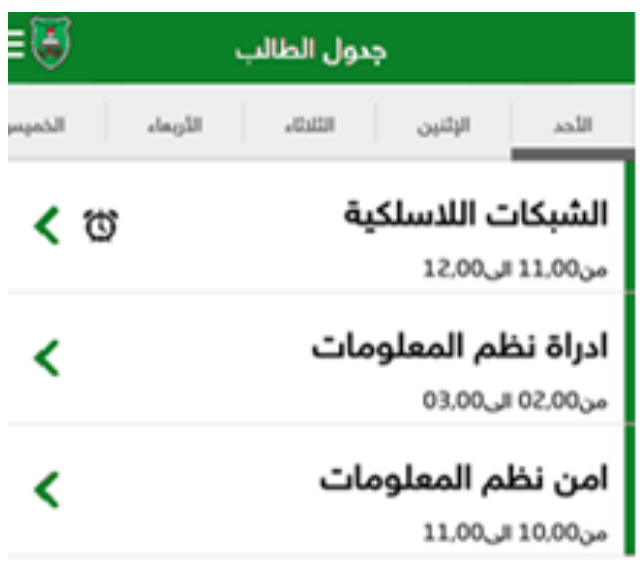

Figure 7. Timetable for the current academic term

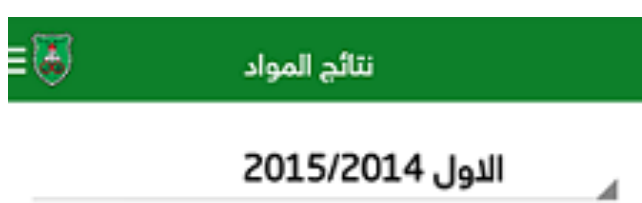

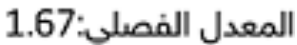

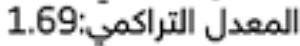

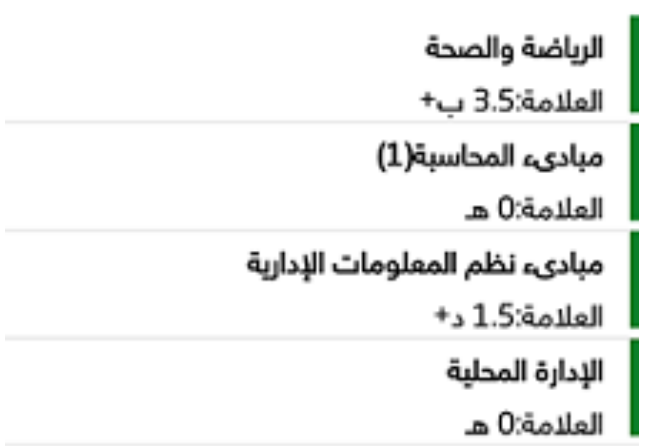

Figure 8. A snapshot of my grades screen

in Fig. 8, clicking on the "My Grades" tab on the main dashboard menu, the student would be able to see their track of grades for the term they are in. Moreover, Grades record would be automatically updated whenever changes have been made on them on the university website, and as long as the student's device is connected to the internet.

The final design future, wish is also considered as crucial feature of the UniApp approach is the lecture alarm and notes. In order, to maintain student engagement with the university environment, it was important to alarm students when their scheduled lecture is due. This feature also allows the student to attach a note with the alarm notification as seen in Fig. 9.

The usage of the UJApp environment also shows that students were heavily engaged with the application. Fig.11 shows the number of screen views, which reached over a million screen view within a single academic term. It also the average number of screen viewed was (4.82) screen per session, which indicates that students have used most of the UJApp main academic features. Also, that the average of session duration was about (3:43) minutes. This 


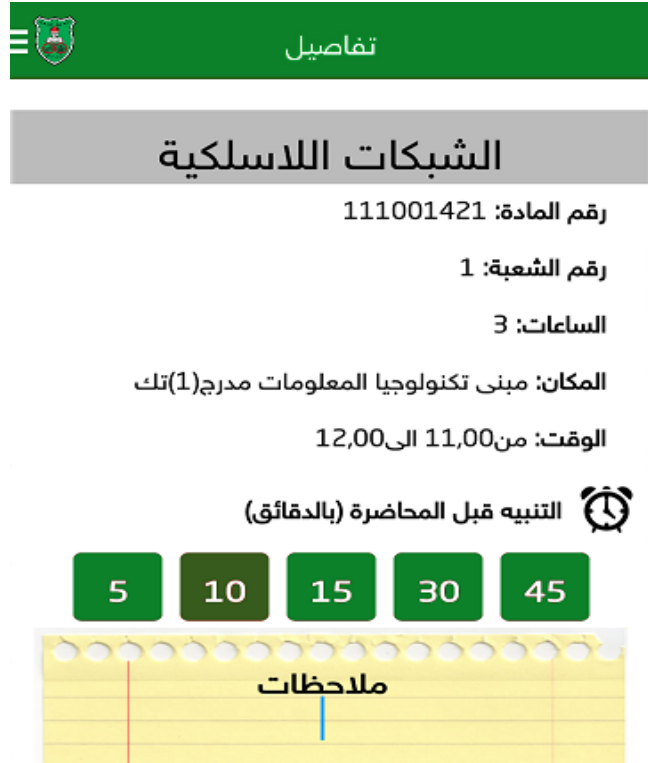

Figure 9. A snapshot of Alarm and Notes screen

indicates that the environment presented an easy to acquire information that assisted students during their registration process, and helped them to understand their current academic state and to be able to plan for the next term module registration. This claim is also supported by the user feedback that can be accessed through Google Play Store [13].

\section{EVAlUATION OF UNIAPP APPROACH}

The UniApp approach has been adapted by a number of public and private universities in Jordan. In particular, this paper presents the test case of UJApp which is a customized mobile application for the University of Jordan. The usage of UJApp was captured through Google Analytics
[12] which provides an in-depth analysis of application usage as well as user rating and feedback.

Fig. 10, shows the number of University of Jordan students who downloaded the UJApp over the first term of the 2014-2015 academic year. The total number of downloads was $(12,206)$ until the date of data capture. This show how important was for students to have such approach to help them during their study. The figure shows that many students download the application at the beginning of the term, during the module registration period. Then, by the end of the term, the figure shows that the rest of the students continued downloading the application on even a higher rate. By this time of academic term at the UJ, students start to plane for module registration for the next term, which explain the need to have a clear idea about their academic progress and what modules needed to achieve their graduation requirement in time.

Although a small number of student opted in to submit a review for the UJApp environment (905 reviews). However, the available review provides a clear indication of what students thought about the environment and how it helped them in understanding their academic state. The feedback optioned through Google Analytics [11] shown in Fig. 12, shows that students highly rated the application through Google Play with average star rating of 4.42. The provided reviews are considered as crowd sourced indicator of the environment quality. And high ratings and positive reviews affect the viability of the environment feasibility [14].

According to the students' positive feedback, the application was amazing, easy to use and they also hoped for even more functionalities such as online module registration, which is currently provided by the UJ's own registration system. On the other hand, a small number of students who reviewed the UniApp environment (9.1\%) were not satisfied with it and provided a less than average review ( two stars or less).

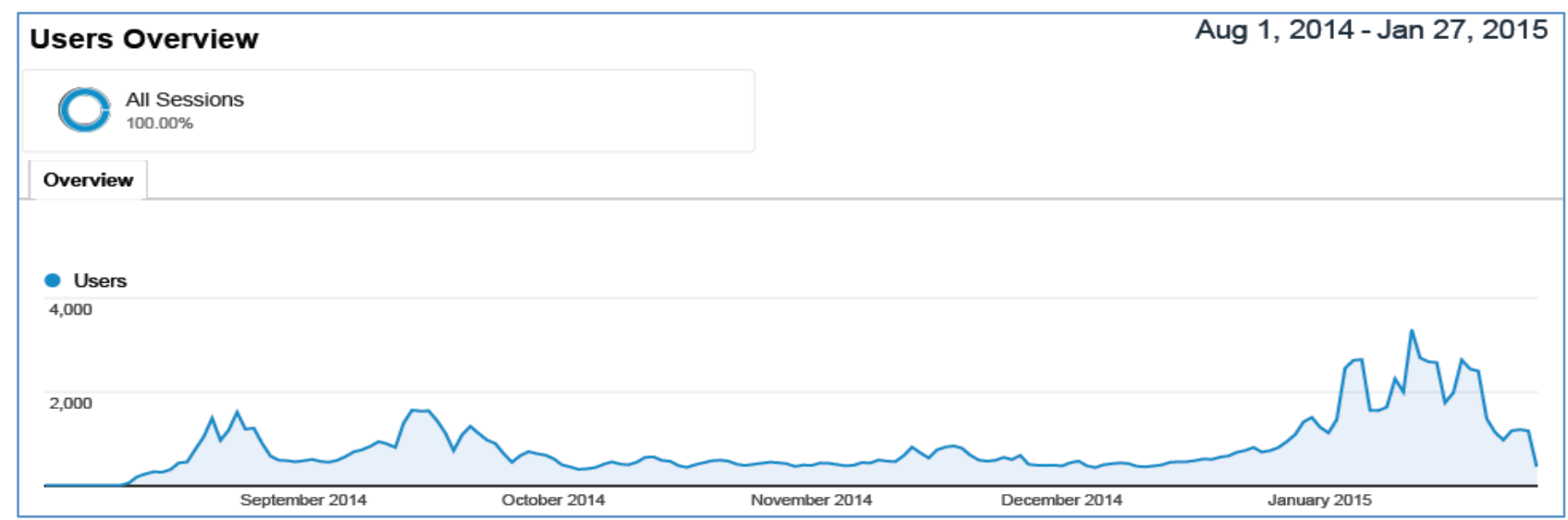

Figure 10. Number of UJ students who downloaded UniApp over the first academic term

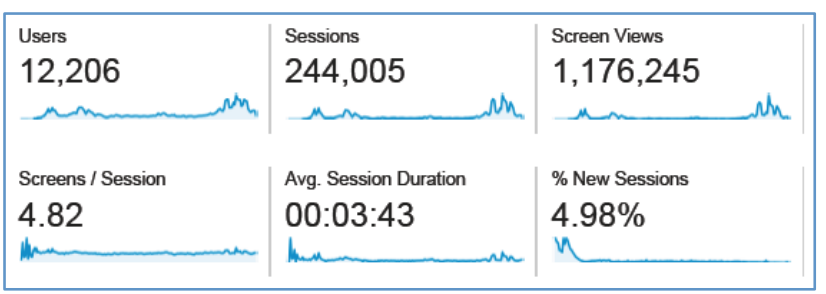

Figure 11. UniApp usage based on session duration and screen views

\begin{tabular}{|llr|l|}
\hline RATINGS \& REVIEWS & & \\
\hline$\#$ of Ratings & $\star \star \star \star \star$ & 649 & Average Rating \\
$\mathbf{9 0 5}$ & $\star \star \star \star \star$ & 113 & $\mathbf{4 . 4 2}$ \\
& $\star \star \star \star \star$ & 60 & \\
& $\star \star \star \star \star$ & 36 & \\
& $\star \star \star \star \star$ & 47 & \\
& & & \\
& & & \\
\hline
\end{tabular}

Figure 12. UniApp rating based on UJ students' feedback 


\section{CONCLUSION AND FUTURE WORK}

In this paper we presented the UniApp approach, which is based on providing students with many important services through the use of their own smart devices. A test case of University of Jordan m-learning environment implemented through UJApp was presented. The evaluation of the environment was based on students' usage, rating and feedback about their experience with UJApp. The results shows that UniApp environment has efficiently helped students to be engaged with their university, understand their study plan, and easily view registered term schedule and their module's based information. This approach was achieved without the need to access the university secured database or violating their privacy and security. The next step in the UniApp approach will take in consideration students' feedback such as including module online registration, and student generated content as main features of UniApp environment. Then, we are planning to provide students with an eAdvisor tool that will help students in choosing the right modules based on their current academic state. On the social side of the application, university map and classroom locater service will also be provided in the future updates.

\section{REFERENCES}

[1] Weller, M., "Virtual Learning Environments: Using, Choosing and Developing your VLE". 2007: Routledge.

[2] Bromage, A., "The relationship between students' orientations to learning and their use of and feelings about a VLE". Virtuality and Education A Reader, 2004.

[3] Hassan, M..Al-Saadi., Jehad, A New Mobile Learning Adaptation Model. International Journal of Interactive Mobile Technologies, 2009. 3: p. 4-7. http://dx.doi.org/10.3991/ijim.v3i4.986

[4] eMarketer. "APAC's Low Internet, Smartphone User Penetration Won't Change Much in Coming Years". 2014 [cited 2015 3March-2015]; Available from: http://www.emarketer.com/Article/APACs-Low-InternetSmartphone-User-Penetration-Wont-Change-Much-ComingYears/1011154.

[5] Chen, G.D., C.K. Chang, and C.Y. Wang, "Ubiquitous learning website: Scaffold learners by mobile devices with informationaware techniques". Computers \& Education, 2008. 50(1): p. 7790. http://dx.doi.org/10.1016/j.compedu.2006.03.004

[6] Crane, L., P. Benachour, and P. Coulton, "Virtual Learning Environments for mobile learning: Constrained by infrastructural and sociological boundaries?" Innovation in Teaching and Learning in Information and Computer Sciences, 2011. 10(1): p. 12-21. http://dx.doi.org/10.11120/ital.2011.10010012

[7] Lefever, R. and B. Currant, "How can technology be used to improve the learner experience at points of transition". 2010.

[8] Webster, M.K. and D. Dyar, "Using a database-driven website to track sensitive data use, in Proceedings of the 33rd annual ACM
SIGUCCS conference on User services". 2005, ACM: Monterey, CA, USA. p. 447-449.

[9] Miami, U.o. The University of Miami on Your iPhone, iPod touch, or iPad. 2011 [cited 2015 5-6-2015]; Available from: http://itunes.apple.com/us/app/umiami/id445067887?mt=8\&ls=1 $\% 3 \mathrm{e}$.

[10] Alabama, T.U.o. University of Alabama on Google Play. 2013 227-2013 [cited 2015 7-3-2015]; 2.5:[Available from: https://play.google.com/store/apps/details?id=com.blackboard.and roid.central.ua.

[11] Ciravegna, F. and A. Lavelli, "Full text parsing using cascades of rules: an information extraction perspective, in Proceedings of the ninth conference on European chapter of the Association for Computational Linguistics". 1999, Association for Computational Linguistics: Bergen, Norway. p. 102-109. http://dx.doi.org/10.3115/977035.977050

[12] Google. "Google Analytics Official Website". 2015 [cited 2015 1-Mar-2015]; Available from: http://www.google.com/analytics/.

[13] UNIApp. "UJApp - Android Apps on Google Play". 2015 [cited 2015 1-March-2015]; Available from: https://play.google.com/ store/apps/details?id=ujapp.applikabletech.ujapp\&hl=en_GB.

[14] Hoon, L., et al., "A preliminary analysis of vocabulary in mobile app user reviews", in Proceedings of the 24th Australian Computer-Human Interaction Conference. 2012, ACM: Melbourne, Australia. p. 245-248. http://dx.doi.org/10.1145/2414536.2414578

\section{AUTHORS}

Dr. Mohammed Hassan is Assistant professor at Software Engineering department, Al-Ahliyya Amman University, Jordan. He Did his M.Sc. and Ph.D. in Information Processing Systems at Baku State University, Azerbaijan. He has joined the academia sector since 2001. His research areas are Mobile-learning, Middleware, elearning, e-government, and software development methodologies.mhassan@ammanu.edu.jo

Dr. Fuad Alhosban is Assistant professor at the College of Computing and Informatics, Saudi Electronic University, Saudi Arabia. He completed his MSc in Computer Science from Coventry University, UK. He was awarded his $\mathrm{PhD}$ in Computer Science from Durham University, UK. His Research interests are: Interactive Visualization, Auralization, Multimedia, Learning Environment and HCI. f.alhosban@seu.edu.sa

Dr. Mou'ath Hourani is Associate professor at Software Engineering department, Al-Ahliyya Amman University, Jordan. He did his Ph.D. in Software Engineering at University of Newcastle/Australia. He has joined the academia sector since 2008. His research areas are Business intelligence,e-learning, Strategic enterprise management, software oriented architecture, and Mobile-learning. mouath.hourani@ammanu.edu.jo

Submitted 25 June 2015. Published as resubmitted by the authors 30 August 2015. 